\title{
SEJARAH LISAN INTEGRASI PAPUA KE INDONESIA: PENGALAMAN ORANG KAIMANA PADA MASA TRIKORA DAN PEPERA
}

\author{
Cahyo Pamungkas \\ Pusat Penelitian Sumberdaya Regional, Lembaga Ilmu Pengetahuan Indonesia \\ cahyopamungkas@gmail.com
}

\begin{abstract}
This article is addressed to describe the political development in Kaimana, West Papua, at the integration period between 1961 and 1969. The method of research employed by this study is oral history, which emphasize on interviews to several informants in Kaimana. However, the result of interviews were supported by archival studies to find accurate findings and analysis. Based on several historical narration, it is founded that the history of Kaimana in the Indonesian context is the history of struggle against Dutch colonialism. The history has built the Indonesian representation in Papua which always deal with Papua political identity constructed by nationalist Papua. From oral history, we reveal that Dutch officials and some groups of Papua implanted Papuans political identity based on racial differences. Another finding is the story about Let col. Untung Syamsuri, former Cakrabirawa commander, who were suspected involved in the Indonesian Communist Part coup in 1965. From several interviews, native people of Kaimana admired and respected a lot to this officer due to he has represented Indonesia in more humanize.
\end{abstract}

Keywords: integration, Pepera, Kaimana

\begin{abstract}
ABSTRAK
Artikel ini bertujuan untuk mendeskripsikan proses politik di Kaminana, Papua Barat, pada saat periode integrasi di tahun 1961 dan 1969. Metode penelitian ini menggunakan strategi sejarah lisan dan menekankan pada wawancara terhadap beberapa informan di Kaimana. Kemudian, hasil dari wawancara didukung pula dengan kajian arsip untuk menemukan keakuratan temuan dan analisis. Berdasarkan beberapa cerita sejarah, sejarah Kaimana dalam konteks Indonesia adalah sejarah tentang perlawanan rakyat dengan kolonialisme Belanda. Sejarah dibangunan dari representasi Indonesia, di mana selalu terkait dengan politik identitas masyarakat Papua. Berdasarkan sejarah lisan, terungkap bahwa Belanda dan beberapa orang Papua menanamkan bahwa identitas politik papua harus berdasar pada perbedaan ras. Selain itu, temuan lain adalah terkait cerita dari Letnan Kolonel Untung Syamsuri, mantan komandan Cakrabirawa, yang terlibat dalam "kudeta" Partai Komunis Indonesia di tahun 1965. Dari beberapa wawancara, orang asli Kaimana lebih mengagumi dan menghormati petugas Indonesia karena lebih humanis.
\end{abstract}

Kata kunci: integrasi, Pepera, Kaimana

\section{PENDAHULUAN}

Menurut sejarawan Australia, Richard Chauvel, Fakfak dan Kaimana pada tahun 1960an ialah salah satu arena kontestasi antara identitas politik kePapuaan dan ke-Indonesiaan. Salah satu pendukung dari kelompok proIndonesia yang cukup signifikan di daerah ini adalah Gerakan Rakyat Indonesia Baru (GRIB). Sementara, anggota- anggota New Guinea Raad yang merupakan pelopor dari nasionalisme Papua dari daerah tersebut ialah Nicholas Tanggama dan Muhammad Achmad Aituarauw, putra Raja Komisi Achmad Aituarauw yang berasal dari Kaimana. Ahmad maupun Tanggama dikenal sebagai tokoh politik yang memperjuangkan Papua merdeka dan bekerja untuk kepentingan orang Papua. Namun sikap politik mereka tentu saja ber- 
sifat dinamis sesuai dengan konteks politik pada masing-masing zaman.

Papua merupakan identitas politik dominan yang dikonstruksi oleh para elit intelektual pada masa persiapan dekolonisasi di sebagian besar daerahdaerah di Tanah Papua. Namun di Serui dan Fakfak, ke-Papua-an ini dikontestasikan dengan identitas politik keIndonesia-an. Fakfak dan Kaimana merupakan basis paling kuat dari nasionalisme Indonesia di Tanah Papua pada masa awal integrasi dengan Indonesia maupun pada masa kebangkitan rakyat Papua tahun 1998. Ke-Indonesiaan telah memiliki akar sejarah yang panjang di daerah ini mengingat para pendatang dari Indonesia seperti Seram, Buton, dan lain-lain telah datang dan menetap di daerah ini sejak masa Kerajaan Namatota jauh sebelum Belanda mendirikan Benteng Fort Du Bus di Teluk Triton. Mereka telah melakukan perkawinan campuran dan menghasilkan keturunan suku-suku yang sekarang ini disebut sebagai suku pantai (Koiwai) di Kaimana.

Berbeda dengan Teluk Arguni dan Teluk Etna, Kaimana adalah daerah di tepi pantai yang menjadi pusat pemerintahan dari wilayah administratif sepanjang Buruwai sampai dengan Teluk Etna. Selain itu, Kaimana juga menjadi pusat perdagangan yang banyak ditempati oleh para pendatang yang berasal dari Maluku dan Sulawesi terutama di Kampung Seram dan Kampung Buton. Untuk melindungi daerah tersebut pasukan Belanda memusatkan kekuatannya di daerah ini. Menurut catatan resmi Indonesia, hasil pengintaian Angkatan Udara Mandala menunjukkan Kaimana diperkuat antara lain dengan satu kapal fregat, satu kapal perusak, satu kapal selam, dan pesawat tempur Neptune, selain satu batalyon pasukan Marinir. Dua aspek penting yang perlu dilihat terkait dengan Trikora adalah penerjunan pasukan-pasukan TNI di wilayah Kaimana Kota dan peranan tokoh-tokoh Kaimana yang dianggap signifikan secara politik dalam mendukung proses integrasi Papua dengan Indonesia.

Periode 1950-1960 diwarnai dengan pergolakan politik antara para pendukung integrasi Papua ke Indonesia dengan Pemerintah Belanda. Di Hollandia (Jayapura) pada tahun 1951 sejumlah pemuda dan pemudi Irian Barat dan suku-suku lainnya ditangkap karena mendirikan Partai Indonesia Islam yang menentang keras penjajahan Belanda. Pada tahun 1953, terjadi pemberontakan di Fakfak yang dipimpin oleh Abu Talib bin Paris dari Kokas. Pada tahun 1960 terjadi pemberontakan di Kokas Fakfak. Banyak pemuda Indonesia yang terlibat pemberontakan ini dibuang ke Digul untuk beberapa lama. Beberapa pejuang pro Indonesia dan mantan eks Digulis kemudian membentuk Gerakan Rakyat Irian Barat (GRIB) yang menentang penjajahan Belanda melalui berbagai demonstrasi. GRIB di Fakfak melakukan unjuk rasa besarbesaran pada waktu kunjungan Menteri Belanda Bost pada tahun 1962. GRIB mengirimkan resolusi kepada Sekjen PBB pada tanggal 14 Februari 1962, menuntut Irian Barat segera dikembalikan oleh Belanda kepada Republik Indonesia. Sementara para pemuda pro Indonesia juga memilih melarikan diri ke Indonesia secara bergelombang sejak tahun 1949 sampai dengan 1961.

Seorang mantan pegawai telekomunikasi Belanda di Biak mengatakan bahwa informasi penerjunan pasukan Trikora di Teluk Arguni sudah diketahui oleh Belanda. Stasiun Telekomunikasi Jayapura juga menyampaikan tentang penerjunan pasukan payung di sekitar danau Siwiki dan danau Karara di Teluk Arguni (Wawancara Abdul Qodir Kurita, Janu- 
ari 2009). Akibatnya, sebagian dari pasukan Trikora tertangkap atau tertembak mati oleh tentara Belanda. Menurut catatan resmi Paskas TNI-AU, jumlah personil dari TNI, Polri dan relawan yang diinfiltrasikan selama Trikora adalah 1.419 personil dengan jumlah korban jiwa 216 gugur/hilang dan 296 tertangkap (Indobat Community, 2008). Dari permasalahan di atas, penulis tertarik untuk menganalisis secara lebih mendalam berdasarkan penuturan pelaku sejarah tentang peristiwa integrasi Papua yang terjadi di Kaimana.

\section{METODE PENELITIAN}

Penelitian menggunakan sejarah lisan untuk menganalisis bagaimana perkembangan situasi politik di Kaimana pada masa awal integrasi sampai dengan Indonesia. Paper ini juga menelusuri cerita dari masyarakat berkaitan dengan kontestasi politik antara Indonesia dan Belanda di Kaimana terutama Trikora dan Pepera. Bertolak dari penelusuran secara historis sejak pasca kemerdekaan hingga Pepera, diharapkan dapat memperoleh gambaran sekaligus pemaknaan tentang proses konstruksi identitas politik ke-Indonesia-an di Kaimana pada tahun 1960-an. Narasumber yang dijadikan sebagai sumber primer penelitian dipilih berdasarkan keterlibatan dan pengalaman yang mereka alami pada saat integrasi Papua ke Indonesia.

\section{HASIL DAN PEMBAHASAN}

\section{Jalannya Operasi Militer di Kaimana}

Operasi Komando Mandala dilakukan dalam tiga fase yaitu infiltrasi, eksploitasi, dan konsolidasi. Pada fase eksploitasi operasi Komando Mandala telah ditetapkan beberapa sasaran pokok serangan terbuka seperti Fakfak, Sorong, Kaimana, Jayapura, dan Merauke (Imran, 1971: 115-116; Imparsial, 2011: 34). Kaimana kemudian menjadi sasaran dari berbagai operasi militer dalam tiga fase tersebut lewat berbagai matra baik darat, laut, dan udara.

Kekuatan militer Belanda di Kaimana pada awalnya hanya terdiri atas 1 pleton marinir berjumlah 54 orang. Kemudian memperoleh bantuan Kesatuan B Pelopor di bawah komando Letnan Satu N. Berharz yang tiba dengan pesawat pada 28 Juli 1960. Kesatuan itu sendiri di bawah komando Kapten M.R. van den Dorpe yang tiba dengan kapal "Grote Beer" pada 12 November 1960 di Kaimana. Selanjutnya ditempatkan marinir berjumlah 250 personil untuk memperkuat pertahanan menjelang fase infiltrasi tentara republik (Nortier dan de Leeuw [tanpa tahun]).

Dalam fase infiltrasi, Angkatan Laut RI (ALRI) menggelar beberapa operasi militer. Operasi Badar Lumut dilakukan di Kaimana pada 28 Juni 1962 yang tugasnya melakukan silent landing untuk memberikan bantuan armada infiltrasi lewat laut yang melibatkan Angkatan laut. Operasi ini dikendalikan langsung Komando Depan AL Mandala yang dipimpin oleh Deputi Panglima AL Mandala Kol. Laut M. Subarkah (Imparsial, 2011: 37).

Pelaksanaan infiltrasi melalui matra udara dipimpin oleh Panglima Angkatan Udara Mandala, Komodor Udara Leo Wattimena. Lewat jalur udara dilakukan 8 operasi militer dalam fase infiltrasi, beberapa di antaranya menjadikan Kaimana sebagai target sasaran. Operasi pertama adalah Operasi Banteng II (Banteng Merah) yang dikomandoi Kapten Pnb Santoso dengan sasaran Kaimana untuk menerjunkan 1 tim RPKAD/Kopasgat sebanyak 40 personil yang dipimpin 
oleh Letda Heru Sisnodo. Operasi militer kedua adalah Operasi Kancil II yang ditugaskan khusus untuk mengintai dan melakukan pemotretan di Kaimana. Operasi Kancil II berkekuatan satu kompi pasukan dengan menggunakan 3 pesawat C-47 dan dikawal pesawat B-25 dengan pilot Kapten Pnb M Abdulkadir.

Masuk pada bulan Juli 1962 tujuan operasi militer mulai berubah karena muncul usulan perdamaian yang ditawarkan PBB. Tujuan operasi militer kemudian hanya untuk penambahan pasukan dan logistik di daerah penerjunan Merauke dan Kaimana. Operasi militer ketiga pada 31 Juli 1962 adalah Operasi Rajawali dengan menerjunkan 71 personil dari Kompi Yon 328 Siliwangi yang dipimpin Letnan Atma di Kaimana. Operasi militer keempat adalah Operasi Lumbung yang bertujuan memasok logistik tambahan kepada pasukan yang ada di Irian Barat, khususnya Kaimana dengan menggunakan pesawat Hercules yang dipiloti Mayor Pnb Nayoan. Operasi militer terakhir dalam fase infiltrasi adalah Operasi Jatayu pada 14 Agustus 1962 yang bertugas untuk menerjunkan pasukan dan perbekalan di daerah Sorong, Merauke, dan Kaimana. Untuk Kaimana, nama gugus tugasnya adalah "Gagak" dengan menggunakan pesawat Hercules yang dipiloti Mayor Mhd Slamet dan mengangkut 141 personil Yon 454/Para pimpinan Mayor Untung (Imparsial, 2011: 38-42).

Namun fase eksploitasi urung dilaksanakan karena terjadi perubahan politik dari pihak Belanda yang menyetujui usulan damai yang ditawarkan PBB. Jika fase eskploitasi dilaksanakan rencananya akan dilakukan operasi militer terbuka pada akhir 1962 yang melibatkan lebih dari 70 ribu personil dari seluruh kekuatan matra (darat, laut, udara) (Imparsial, 2011: 42-43).

Pada fase konsolidasi pasca Per- janjian New York, pasukan yang sudah berada di Papua dikonsentrasikan di Sorong dan Kaimana, yang lalu dipecah menjadi 4 detasemen yang disebar pada 4 lokasi yakni Merauke, Kaimana, Fakfak, dan Sorong. Pimpinan dari detasemen B yang menempati wilayah Kaimana adalah Mayor Untung Syamsuri. Detasemen yang berlokasi di Kaimana ini terdiri dari Kompi Garuda Putih Yon 454/Diponegoro, Kompi Gagak Yon 454/Diponegoro, Kompi Rajawali Yon 328/Siliwangi, Tim Banteng II/RPKAD, 10 personil Kopasgat (Imparsial, 2011: 46).

Namun terkait dengan peran Mayor Untung Syamsuri terjadi perbedaan antara catatan resmi Pemerintah Indonesia dengan cerita lisan yang berkembang. Cerita lisan di Teluk Arguni dan Kaimana banyak berfokus pada "kepahlawanan, keberanian, dan kebaikan" Mayor Untung yang pada akhirnya terlibat dalam "G 30 S/PKI." Sementara catatan resmi pemerintah tidak menyebutkan peran Mayor Untung secara khusus dalam operasi ini. Hal ini dapat dipahami mengingat sejarah pada masa Orde Baru memang bertujuan untuk menghapus memori rakyat Indonesia terhadap tokoh-tokoh yang dianggap "terlibat G 30 S/PKI" walaupun tokoh-tokoh tersebut sebenarnya sangat berjasa kepada negara.

Dalam catatan resmi pemerintah disebutkan bahwa operasi penerjunan di Kaimana dilakukan beberapa kali tanpa menyebut secara spesifik lokasi penerjunannya apakah di Teluk Arguni atau Kaimana Kota (Djamhari, 1995: 247). Seluruh operasi penerjunan payung menjadi tanggung jawab Panglima Angkatan Udara Mandala yakni Komodor Leo Wattimena. Adapun operasi penerjunan di daerah yang sekarang ini disebut sebagai Kabupaten Kaimana mencakup beberapa kali, yaitu 
sebagai berikut. Pertama, Operasi Banteng II (Banteng Merah) dipimpin Letda Heru Sisnodo, terdiri atas 40 orang RPKAD (Resimen Para Komando Angkatan Darat) dan PGT-AU (Pasukan Gerak Tjepat Angkatan Udara). Pasukan ini diberangkatkan dari Lapangan Terbang Pattimura (Laha) Ambon dan mendarat di Pasir Putih, Kaimana pada 26 April 1962.

Kedua, Operasi Kancil II pada 17 Mei 1962 terdiri atas 3 buah pesawat Dakota C-47 dikawal Pembom B-25 yang mengangkut 1 kompi pasukan. Penerbang Dakota adalah Kapten Penerbang Abdulkadir.

Ketiga, Operasi Garuda Putih diterjunkan pada 15 Mei 1962 sebanyak 27 orang, 17 Mei 1962 sebanyak 27 orang, dan pada 25 Mei 1962 sebanyak 68 orang. Mereka berasal dari Batalyon 454 Diponegoro dan PGT di bawah Letnan Idrus. Asal pemberangkatkan dari Lanud Pattimura, Laha Ambon.

Keempat, Operasi Lumbung dengan tujuan untuk penambahan logistik di bawah penerbang Mayor (Penb) Nayoan pada tanggal 26 Juni 1962. Kelima, Operasi Rajawali, dilaksanakan pada tanggal 31 Juli 1962 untuk penambahan pasukan, terdiri atas 71 orang dari batalyon 328/Siliwangi di bawah pimpinan Letnan Atma. Keenam, Operasi Jatayu dilaksanakan pada tanggal 14 Agustus 1962. Pasukan yang diturunkan di Kaimana adalah Pasukan Gagak terdiri atas 141 orang anggota Batalyon 454/Diponegoro di bawah pimpinan Mayor Untung Syamsuri.

\section{Penerjunan di Distrik Kaimana}

Berdasarkan catatan pemerintah pasukan yang diterjunkan di Pasir Putih Kaimana berjumlah 40 orang yang terpencar-pencar (Djamhari, 1995: 249). Kelompok kecil pasukan di bawah
Letnan Heru Sisnodo yang dapat masuk Kota Kaimana setelah penandatanganan Perjanjian New York hanya berjumlah 16 orang. Anggota pasukan pasukan lainnya, Prada Sarip tertangkap Belanda dan ditahan di Biak. Di tengah perjalanan mereka menitipkan dua anggota pasukan yang patah kakinya kepada penduduk kampung tetapi penduduk tersebut menyerahkan dua anggota TNI tersebut kepada Tentara Belanda.

Martinus Naguasai, tokoh masyarakat Forumajaya menyebutkan bahwa sasaran penerjunan pasukan Trikora di Kaimana adalah di Pasir Putih (20 km dari Kaimana Kota) dan Tofromi (dekat Sisir, Kaimana) (Wawancara 1 Februari 2009). Menurutnya, untuk merespon penerjunan tersebut, Tentara Belanda membagikan senjata api ke tokoh-tokoh masyarakat kampung untuk melawan tentara Indonesia. Dari Pasir Putih pasukan payung berjalan ke Kaimana melalui Furnusu dan menyebar ke Nanggaromi, Air Kasih, dan Murano. Dua orang anggota pasukan Indonesia tertembak pada saat menokok sagu di Esetna karena penduduk setempat melapor kepada Bestuur Kaimana. Belanda langsung mengirimkan pasukan ke Air Kasih dan Furnusu dan menembak dua anggota TNI di Esetna.

Oktavianus Safara, saksi sejarah dari Kampung Morano mengatakan bahwa ada operasi penyerangan TNI terhadap Pos Belanda di kampung ini (Wawancara 1 Januari 2009). Pos itu dijaga oleh ratusan tentara Belanda dan orang Papua. Tentara Indonesia ragu menembak karena lawan yang dihadapi ialah orang Papua. Hal ini wajar karena Presiden Soekarno melarang para tentara Indonesia untuk menembak orang Papua yang dianggap sesama saudara dan orang Indonesia. Dipan Wefete, seorang saksi sejarah dari Kampung Gusimawa Teluk Arguni, menceritakan 
bahwa pasukan payung yang diterjunkan di Kaimana mendapat tembakan dari tentara Belanda (Wawancara 23 Desember 2008). Tetapi karena malam hari, tembakan mereka tidak ada yang kena sasaran. Setelah itu, tentara dan polisi Belanda mempersiapkan persenjataan lengkap termasuk meriammeriam di sepanjang pantai dari Pasir Putih sampai Coa. Imam Ubas Nabombo, saksi sejarah lainnya mengaku mendengar baku tembak antara pasukan Indonesia dengan Belanda di Kampung Sisir (Wawancara 19 Januari 2009). Pada waktu malam, pasukan Indonesia turun menyerang pangkalan Belanda. Belanda menempatkan Polisi dan PVK dari orang Papua pada garis paling depan.

Cerita tentang keterlibatan orang Papua sebagai polisi Belanda yang membunuh pasukan payung dibantah oleh salah seorang mantan polisi Belanda. Teriyanus Kotipura, mantan Mobile Police, menceritakan bahwa pada masa pendaratan tentara Indonesia (Tentara Trikora), ia ikut menangkap tentara Indonesia di beberapa tempat seperti di Karora, Berari, Seraran, Sisir, dan Tanggaromi (Wawancara 24 Januari 2009). Menurutnya, mereka tidak menembak tentara Indonesia karena ada instruksi dari pemerintah Belanda untuk tidak menembak pasukan Indonesia jika mereka tidak melawan dengan tembakan. Sepanjang ingatannya tidak ada tentara Indonesia yang ditembak oleh Polisi Belanda, kecuali salah seorang anggota tentara Indonesia yang terjun di Faranyau yang patah kakinya saat mendarat karena terbentur oleh pohon melinjo dan salah seorang anggota lagi yang ditembak oleh komandannya sendiri, Letnan Heru Sisnodo.

Sebagaimana terjadi di Teluk Arguni, ada beberapa orang pendukung Indonesia dari Kaimana yang melarikan diri ke Maluku. Menurut Imam Ubas, salah satunya ialah Alaudin Lawai, yang mencoba melarikan diri ke Tual dengan mencuri perahu Johnson milik Ampong Kang (Wawancara 24 Januari 2009). Dia melarikan diri karena ditempeleng oleh orang Belanda sewaktu pulang sekolah. Dari Kaimana, Alaudin pergi ke hutan bakau Kalinama. Setelah malam, melanjutkan pergi ke pulau Venue dan terus sampai ke Tual. Cerita yang lain adalah Adum Malik, melarikan diri karena bermusuhan dengan seorang polisi Belanda. Dahulu ketika di penjara Fakfak, polisi ini memaksa Adum Malik untuk melakukan hal yang merendahkan derajatnya.

Sesudah penandatanganan Perjanjian New York dan penyelenggaraan pemerintahan sementara oleh UNTEA, Pasukan Indonesia mengambil alih kekuasaan pemerintahan dan pengawasan di Kaimana dari PBB. Pasukan-pasukan Indonesia berdatangan dari kampung Sisir dipimpin oleh Letnan Heru Sisnodo dan dari Teluk Arguni yang dipimpin oleh Mayor Untung pada tanggal 1 Mei 1963.

\section{Penerjunan Pasukan Payung Di Teluk Arguni}

Cerita penerjunan pasukan Trikora di bawah Mayor Untung telah menjadi legenda di tengah masyarakat, terutama tentang kepribadian Mayor Untung dan misi pasukannya untuk membebaskan Kaimana dari Belanda. Di Kaimana banyak masyarakat yang menjadi pendukung Indonesia. Kota Kaimana menjadi target kerena merupakan pusat kegiatan politik dan perdagangan di Selatan Papua.

Mayor Untung Syamsuri dengan anak buahnya terjun di Lembah Gunung Genova, Arguni, pada bulan Agustus 1962 (Wawancara 22 Desember 2008). Tokoh masyarakat yang berperan 
dalam membantu operasi penerjunan ini ialah Kepala Kampung Seraran, Hamzah Furu, yang juga merupakan Wakil Komandan Gerakan Rakyat Indonesia Bersatu (GRIB). Hamzah Furu menjadi penghubung antara Pasukan Gagak dengan masyarakat di Teluk Arguni yang bertugas memobilisasi orangorang kampung untuk memberikan makanan dan mendayung perahu yang digunakan untuk mengangkut tentara Indonesia. Hamzah Furu bersama Abdullah Werfete juga membantu penyusupan dan penerjunan pasukanpasukan TNI lainnya dari Teluk Arguni sampai dengan Teluk Etna. Misalnya, memberitahukan sandi kapal-kapal atau perahu-perahu yang mengangkut pasukan TNI membawa bendera bertulisan ARAY yang artinya adalah ipar. Selain di Gunung Genova, Pasukan Trikora juga diterjunkan di G. Karora dan G. Lewai.

Penerjunan di Siwiki dilaksanakan waktu Subuh dengan menggunakan pesawat Hercules di Lembah Genova disaksikan oleh Abdul Mat Puarada, penduduk Kampung Seraran (Wawancara 5 Januari 2009). Sesampai di darat, pasukan mencari posisi dan mencari masyarakat setempat untuk menyampaikan tujuan pendaratan. Pasukan juga mencari basis di tengah masyarakat dengan cara menyebar ke dalam kampung-kampung pada siang hari, dan berkumpul kembali pada malam hari di suatu tempat. Sebagai penanda, kepala mereka dibalut dengan ikatan kain berwarna merah putih. Setiap bertemu orang di Kampung Seraran, mereka bertanya: "Kamu orang Islam kah?." Orang-orang kampung menjawab: "Ya Kami orang Islam", mereka menjawab: "Alhamdulilah kita bersaudara." Baru mereka memberikan tujuan kedatangannya bahwa mereka sedang membebaskan orang-orang Papua dari penjajahan Belanda.
Masyarakat membantu pasukan payung dengan mengumpulkan hasil kebun seperti sagu, keladi, pisang untuk disimpan di satu tempat dan membawakan peralatan-peralatan TNI termasuk peluru untuk dibawa ke tempat yang lebih aman di Wellanias (Wawancara Abu Werfete, 24 Desember 2008). Dari Kampung Seraran, mereka bergerak turun sampai ke Siser I. Mayor Untung Syamsuri membangun basis pertahanannya di Kampung Sisir.

Konflik antara Belanda dan para pendukung integrasi dengan Indonesia memaksa sebagian orang Papua melarikan diri ke wilayah Indonesia. Salah seorang pelaku sejarah dari Kampung Warwasi, Daud Werfete, menceritakan bahwa dia mencoba melarikan diri ke Indonesia karena kecewa ketika Pemerintah Belanda mengatakan "sudah tua masih mau sekolah lagi" (Wawancara 24 Desember 2008). Padahal umurnya pada waktu itu masih 7 tahun. Daud Werfete bersama Usman Furu, Kadir Furu (Seraran), Yonas Guriyan (Buruwai), dan salah seorang guru (bermarga Renyaan) berusaha melarikan diri tetapi tertangkap Belanda. Mereka dilepaskan menjelang operasi Trikora. Sebulan setelah dilepaskan, salah seorang Polisi Belanda Nathaniel Hurima membawa Daud Werfete, Kadir Furu, dan Usman Furu ke Fakfak untuk ditanya alasan mereka melarikan diri ke Indonesia. Setelah menerima penjelasan, Polisi Belanda membebaskan mereka bertiga untuk kembali ke Kaimana. Sebelum kembali ke Kaimana, mereka bertiga membeli pakaian berwarna merah putih dan sebagian orang-orang di situ menganggap mereka pro-Indonesia. Waktu mereka bertiga akan dipukul oleh sekelompok orang, Inspektur Polisi Brower mencegahnya.

Sementara itu, Fredrik Essuruw dari kampung Warwasi bersama Matias Waita dan Gerson Essuruw mencoba 
melarikan diri ke Maluku (Wawancara 24 Desember 2008). Namun, sesampai di dekat Lapangan Udara di Coa, Kaimana, Fredrik ditahan oleh polisi Belanda. Sedangkan, Matias dan Gerson melarikan diri menggunakan perahu Johnson. Mereka yang berhasil melarikan diri pada waktu itu ialah Gerson Esuru, Matias Waita, Baco Puarada dan Abu Watora (Kampung Mahua). Mereka menggunakan perahu mesin 40 PK milik pedagang Cina di Kaimana dan juga perahu mesin 6 PK milik orang Belanda. Catatan resmi pemerintah Indonesia menunjukkan bahwa Gerson Issuruw, yang bergabung dengan pasukan Gerilya 200 (PG-200), dan komandan PG 200 Peltu Jamaluddin Nasution gugur dalam pertempuran di Kota Sorong (Djamhari, 1995: 98).

Sedangkan Robert Essuruw mencoba melarikan diri ke Pulau Seram, Maluku tetapi rencananya diketahui oleh polisi Belanda di Fakfak (Wawancara 22 Desember 2008). Robert Essuruw bersama 20 orang lainnya ditangkap sebelum berangkat dan dikeluarkan setelah Perjanjian New York pada 15 Agustus 1962. Saat keluar dari tahanan di Fakfak, salah satu dari 20 temannya, Ishak Telusa, ditembak oleh polisi Belanda pada jam 1 malam, 17 Agustus 1962.

Peristiwa penerjunan di Teluk Arguni juga menyebabkan tragedi gugurnya para pejuang Trikora pada saat penerjunan maupun ketika bertempur dengan Pasukan Belanda. Menurut Harun Sabuku, Ketua Suku Irarutu di Kaimana, para polisi Belanda yang berasal dari Papua diduga ikut membunuh pasukan payung karena mereka didoktrin Belanda untuk tidak suka dengan orang-orang Indonesia (Wawancara 1 Februari 2009). Setelah penandatanganan Perjanjian New York, pasukan Trikora berusaha untuk mencari anggota-anggota pasukan yang gugur dan memakamkanya. Seorang saksi sejarah dari Kampung Kambala, Buruwai, Yusuf Narua menjelaskan bahwa pada tahun 1961, orang-orang dari Kampung Kambala pergi ke Teluk Arguni untuk mengambil rangka tentara payung yang gugur dalam penerjunan di Irian Barat (Wawancara 28 Desember 2008). Mereka mendayung sampai di Kampung Barari menuju Danau Siwiki bersama staf UNTEA

Anak Hamzah Furu, Abdullah Furu, dibawa oleh Mayor Untung Syamsuri pada tahun 1962 untuk disekolahkan di Semarang dan ditempatkan di Tegal Wareng, bersekolah dari SD sampai SMA. H. Daluh Sinam seorang perwira penghubung di Kaimana menyarankan Mayor Untung agar mengambil anak Hamzah Furu untuk disekolahkan. Hal ini yang membedakan Mayor Untung dengan para perwira TNI lainnya, sekaligus menunjukan orientasi politik Mayor Untung sebagai seorang nasionalis yang mencoba membangun representasi keIndonesia-an di Papua. Seorang pelaku sejarah, Abdul Mat Puarada sebagaimana orang-orang Kaimana pada umumnya memiliki kesan baik terhadap Mayor Untung Syamsuri. "Waktu itu, Mayor Untung sangat baik, sangat ramah. Mereka mendarat di Lembah Siviki antara Gunung Genova dan Gunung Fuji di Teluk Arguni."

Pada masa Trikora, masyarakat Seraran telah menerima sosialisasi politik sehingga memiliki pengetahuan tentang posisi politik Papua dengan Indonesia. Suatu ketika, Abdul Mat Puarada seorang saksi sejarah bertanya kepada ayahnya, "Trikora itu seperti apa?" Ayahnya menjawab: "Kita, orang Papua, di bawah Belanda itu salah, kita harus bergabung dengan orang-orang Indonesia lainnya yang sudah merdeka, seperti saudara-saudara kita dari Maluku, Bugis, Seram, dan lain-lain.” Dialog 
tersebut menunjukkan bahwa ada sebagian orang Papua pada masa penjajahan Belanda yang merasa dirinya sebagai orang Indonesia. Fakta ini bertentangan dengan kondisi kebanyakan, ketika Belanda melalui pendidikan dasar mengajarkan bahwa orang Papua adalah bukan orang Indonesia tetapi Melanesia.

Menjadi menarik untuk diketahui proses-proses sosial apa yang dialami oleh orang-orang di Teluk Arguni sehingga mereka merasa dirinya orang Indonesia. Pertanyaan dalam konteks sejarah adalah mengapa sebagian orang kampung di Teluk Arguni bersedia membantu TNI?

Tentunya banyak versi yang beragam, dari rekayasa politik sampai dengan mitos kebudayaan Gunung Nabi yang sampai sekarang dipercaya oleh orang-orang Teluk Arguni. Perspektif politik datang dari Thaha M. Al Hamid Sekjend PDP yang juga putra Kaimana. Menurutnya, orang-orang dari Teluk Arguni membantu penerjunan pasukan Payung karena rekayasa politik Indonesia. Hal ini dapat ditelusuri genealogi politiknya dari perdebatan antara Soekarno dan Hatta tentang status Papua dalam wilayah Indonesia (Wawancara 7 Januari 2009). Soekarno mengatakan bahwa seluruh bekas jajahan Belanda ialah termasuk Papua. Namun, Hata berpendapat bahwa orang Papua ialah Melanesia dan memiliki hak untuk merdeka karena takut Indonesia akan dituduh sebagai negara imperialis. Perspektif Thaha tentu saja dipengaruhi pandangan politiknya yang pro-Papua merdeka

Kemudian, AA Maramis mengusulkan agar ditanamkan nasionalisme Indonesia di Tanah Papua. Sugoro ditugaskan untuk menyebarkan pengaruh Indonesia di Jayapura, sedangkan Sam Ratulangi ditugaskan di Serui. Orangorang Rumbati (Fakfak) dan Arguni ju- ga menerima proses sosialisasi tersebut sehingga mereka bersedia membantu para sukarelawan Indonesia yang sesungguhnya adalah tentara. Di antara mereka yang menerima sosialisasi terdapat seorang anak muda militan kader Habib Muhamad Al-Hamid, yang bernama Galin Reasa.

Pendapat yang berbeda diceritakan Harun Sabuku, Ketua Suku Irarutu di Kaimana, yang mengatakan bahwa sosialisasi politik terhadap orang -orang Kaimana dilakukan oleh para eks -romusha (Wawancara 1 Februari 2009). Menurutnya, sesudah Perang Dunia II, banyak para pekerja romusha yang berasal dari Jawa tinggal di Kaimana. Mantan romusha ini mayoritas beragama Islam dan berkata kepada orang-orang Arguni yang beragama Islam bahwa Islam tidak akan berkembang jika Indonesia atau Papua masih di bawah jajahan Belanda, karena itu Papua dan Indonesia harus merdeka dari Belanda.

Harun Sabuku juga menceritakan sesudah penandatanganan Penyerahan Kedaulatan di Den Haag, dari Belanda kepada Indonesia, atas inisiatif Raja Komisi Achmad Aituarauw dan Raja Ombaier diadakan musyawarah kepalakepala kampung untuk menentukan apakah bergabung dengan NIT atau Raja Belanda. Sebelum musyawarah, para kepala kampung sependapat dengan Raja Komisi dan Raja Namatota bahwa mereka akan bergabung ke dalam NIT. Namun secara diam-diam para guru penginjil membisiki para kepala kampung, sehingga pada waktu pengambilan suara, kampung-kampung Kristen memilih pro Belanda dan menang karena jumlahnya lebih banyak dari kampung-kampung Islam. Pandangan ini pada dasarnya memiliki kelemahan karena bersifat simplistis dengan menghubungkan isu agama dengan politik dan juga tidak didukung oleh arsip-arsip resmi pemerintah Belanda. 
Namun menurut Harun, orangorang dari Kampung Kristen di Arguni juga membantu operasi Trikora. Pada masa Trikora, orang-orang Arguni membantu pasukan payung yang mendarat di Gunung Karara dan Danau Siwiki. Meskipun kampung-kampung di sekitar lokasi mayoritas Kristen, para tetua dari kampung ini berhubungan dekat dengan kampung-kampung Islam dan percaya kepada ajaran-ajaran Gunung Nabi. Para tetua itu memerintahkan warga kampung untuk memberi makan pasukan payung. Selanjutnya, kampung-kampung Islam membantu pasukan payung untuk turun ke Sisir.

Pandangan yang berbeda disampaikan oleh Saifudin Furu seorang legiun veteran bahwa orang-orang dari Teluk Arguni membantu pasukan payung karena para tetua dari Gunung Nabi telah berpesan kepada orang-orang Arguni. "suatu saat Belanda akan keluar dari Tanah Papua dan Indonesia akan masuk ke Papua, oleh karena itu jika ada pasukan-pasukan sukarelawan dari Indonesia, bantulah mereka" (Wawancara 22 Desember 2008) Bantuan itu diberikan dengan cara memberikan makanan. Banyak pemuda dari Teluk Arguni bergabung dengan pasukan sukarelawan karena kepercayaan Gunung Nabi yang mengatakan bahwa Papua ini suatu saat akan menyatu dengan saudara-saudaranya di Indonesia.

Menurut Saifudin Furu, orang Kaimana mendukung Indonesia karena mitos bendera merah putih yang bermakna bagi adat istiadat setempat, merah berari perempuan, putih berarti lakilaki (Wawancara 22 Desember 2008). Merah Putih berarti memberikan jiwa bagi kehidupan manusia sehingga menjadi manusia yang bebas. In dimaknai sebagai perjanjian, dis diartikan sebagai keluar, dan Si dipahami sebagai menjadi, Indonesia secara keseluruhan di- artikan sebagai "perjanjian yang mengeluarkan untuk menjadi manusia dari alam." Harapan ayahnya dan para pejuang Trikora pada waktu itu adalah (1) keinginan untuk memperoleh pendidikan sebebas-bebasnya yang dijamin oleh negara dan (2) keinginan untuk memperoleh kebebasan beragama seluasluasnya. Hal ini dikenal dengan semboyan dua hati menjadi satu untuk tujuan kemajuan.

Saksi sejarah lainnya, Sogol Watora membenarkan pernyataan politik Presiden Sukarno bahwa Papua ialah bagian dari Indonesia berdasarkan pendekatan mitologi (Wawancara 22 Desember 2008). Menurut mitos yang hidup di keluarga Watora, seorang lakilaki dari Kaimana bernama Usmani pergi berlayar sambil membawa anjing berwarna putih sedangkan anjing hitamnya ditinggal di Papua dan dititipkan kepada ibunya. Ibunya kembali ke Gunung Sawiah di Teluk Arguni sambil membawa anjing hitam. Kedua anjing itu adalah lambang bahwa orang Papua yang berkulit hitam ialah bersaudara dengan orang-orang Indonesia yang berkulit lebih putih.

Mitos lain yang secara umum menjadi legenda adalah bahwa Papua adalah bagian dari Indonesia karena Soekarno sepulang dari Digul singgah dan menancapkan bendera merah putih di Gunung Nabi. Cerita ini memiliki implikasi luas bagi orang-orang di Teluk Arguni untuk mendukung integrasi Papua ke Indonesia. Padahal, dalam dokumen-dokumen sejarah, tidak ada fakta bahwa Soekarno sempat singgah di gunung ini. Mitos ini juga mendorong pihak-pihak pendukung Papua Merdeka untuk mengibarkan bendera bintang kejora di Gunung Nabi. Salah seorang pensiunan Kapolsek Teluk Arguni, H. Djaeni, menceritakan bahwa dirinya pernah melakukan penangkapan terhadap warga yang ingin mengi- 
barkan bendera bintang kejora pada tahun 1986 di Gunung Nabi.

Berkembang suatu kepercayaan di Teluk Arguni bahwa barang siapa meminta sesuatu di Pigou Gunung Nabi maka akan dikabulkan permohonannya. Kabarnya, pada zaman Jepang, ada seorang Papua yang menancapkan bendera merah putih dan berdoa agar Indonesia merdeka, dan ternyata Indonesia merdeka. Orang Arguni percaya bahwa kemerdekaan Indonesia karena adanya bendera merah putih di Gunung Nabi tersebut. Pada tahun itu, empat warga membawa bendera bintang kejora ke Gunung Nabi namun rencana tersebut dilaporkan ke Kapolsek. Keempat warga itu lalu ditangkap dan diajukan ke pengadilan negeri di Fakfak. Sejak itu, masyarakat menganggap bahwa Papua tidak akan merdeka karena bendera bintang kejora tidak pernah sampai ke Gunung Nabi.

Berdasarkan cerita lisan dan fakta empiris yang diingat masyarakat dapat dilihat bahwa pasukan payung yang diterjunkan di Teluk Arguni mendapat penerimaan yang baik dari masyarakat setempat. Bahkan, nama komandan Mayor Untung Syamsuri, sampai sekarang tetap menimbulkan kesan yang "baik" di mata masyarakat. Penerimaan yang begitu baik tersebut tentunya ada genealogisnya dan historisitasnya baik berbentuk mitos ataupun proses sosial sebelumnya.

Mitos dalam antropologi adalah semacam kesepakatan suatu masyarakat tentang suatu tatanan sosial tertentu. Namun, mitos juga dapat dilihat sebagai pengetahuan lisan masyarakat yang tidak terlembagakan dan dapat berubah seiring dengan perubahan zaman. Melihat suatu mitos tentunya bukan pada bentuk cerita lisannya tetapi sejauhmana kita dapat menangkap makna di balik mitos-mitos tersebut. Misalnya, mitos tentang pengibaran bendera me- rah putih di Gunung Nabi dapat dimaknai sebagai kesepakatan ide tentang integrasi dengan Indonesia yang disepakati oleh orang-orang tua dari sukusuku yang telah menerima sosialisasi politik. Mitos itu sendiri pada hakekatnya tidak dapat dipisahkan dari proses sosialisasi sebelumnya, apakah dalam bentuk sosialisasi politik atau relasi ekonomi.

Perlu menjadi catatan bahwa interaksi orang-orang Kaimana terutama Koiwai dan Teluk Arguni terhadap pendatang dari luar Kaimana telah ada sejak kira-kira abad ke-16 melalui hubungan perdagangan. Ketiadaan mitos dan proses sosialisasi seperti di Arguni di daerah lain menjadikan penerimaan masyarakat menjadi problematis. Paparan berikut tentang penyusupan di Teluk Etna yang lebih banyak cerita kegagalannya daripada keberhasilan.

\section{Penyusupan Di Teluk Etna}

Teluk Etna terletak di bagian timur Kabupaten Kaimana berbatasan dengan Kabupaten Timika, mencakup kampung-kampung di sekitar Teluk Etna dan Danau Yamor. Daerah ini menghadap langsung ke Laut Arafura. Pasukan Trikora mendarat di Teluk Etna dengan menggunakan perahu kecil dari tengah laut pada waktu malam. Sebagian besar kampung di Teluk Etna beragama Kristen dan lebih mendukung Belanda daripada Indonesia. Oleh karena itu lebih banyak cerita kegagalan daripada keberhasilan, tempat Letnan AJ Dimara dan Letnan Antaribaba tertangkap oleh polisi Belanda setelah anak buanya gugur dalam kontak senjata.

Menurut catatan Yayasan Badan Kontak Keluarga Besar Perintis Irian Barat (1995), di Teluk Etna pada tahun 1954 telah terjadi pertempuran antara pasukan Belanda dengan pemuda Irian 
Barat. Para pemuda Indonesia di bawah pimpinan Dhimara bertujuan mengusir pemerintahan penjajah Belanda. Catatan tersebut mungkin benar karena dalam dokumen operasi Trikora tidak ada kisah pendaratan Letnan AJ Dimara di Teluk Etna pada tahun 1960-an. Catatan yang ada justeru merujuk pada Letnan Antaribaba. Mantan Bestuur Mampioper dalam tulisannya mengatakan bahwa Dhimara ini adalah Letnan AJ Dimara yang menyusup di Teluk Etna dengan menggunakan nam a m a "Mampioper."

Sedangkan Letnan Antaribaba adalah komandan pasukan gerilyawan 100 yang diberangkatkan dari Kepulauan Aru pada 27 November 1960 berdasarkan perintah operasi No. 1/ P.O.D.L/7/1960. Sasaran pendaratan adalah Teluk Etna dengan jumlah anggota pasukan mencapai 29 orang bersenjata lengkap. Tugas PG 100 adalah melakukan kegiatan inteligence untuk kepentingan operasi setempat dan usaha pendaratan secara besar-besaran. Selain itu juga membuat daerah basis gerilya dan mengadakan perang wilayah di Irian Barat.

Moy Amir Kamakaula, salah seorang saksi sejarah, mengatakan bahwa penduduk Kampung Kayu Merah yang merupakan daerah paling depan Teluk Etna, membantu menyiapkan makan dan bekal kepada pasukanpasukan Indonesia yang masuk melalui Teluk Etna (Wawancara 21 Januari 2009). Pasukan datang secara berkelompok dan melakukan penyamaran. Perjalanan Letnan Dimara ke Teluk Etna diantar oleh kakaknya yang bernama Doria Kamakaula dan Hamid Kamakaula. Mereka berangkat dari Kayu Merah ke Teluk Etna. Letnan Dimara mengaku sebagai penduduk lokal yang ingin pergi ke Teluk Etna. Kakaknya tidak mengetahui dan tidak menyangka bahwa orang yang menumpang perahu mereka adalah Letnan Dimara, pasukan dari Indonesia. Setelah Letnan Dimara ditangkap, kedua kakaknya dipenjara selama satu tahun di Kaimana dengan tuduhan membawa merah putih dan dicurigai ingin menyebarkan agama Islam di Teluk Etna. Pada waktu itu merah putih dan Islam dianggap sebagai simbol politik Indonesia.

Yakobus Karafei, Kepala Suku Kenafeta di Kiruru, mengatakan bahwa pasukan Letnan AJ Dimara mendarat di Tupai (belakang Kiruru) (Wawancara 4 Februari 2009). Pasukan menggunakan perahu layar dari kapal besar di Tanjung Boy, menuju ke Etnabay dengan diantar oleh Andreas Werebai. Ketika tiba di Etnabay, Dimara dan pasukannya menangkap Ophayn Van Klinken, komandan Polisi Belanda dan membawanya ke Seram. Dua orang polisi Belanda lainnya Kessau Mairuma dan Ferdinand Waterpao meloloskan diri dari serangan pasukan Dimara di Etnabay (Wawancara 4 Februari 2009). Perahu layar Dimara terus menghindar dari Etnabay ke Essanuai (dekat Kiruru). Sesudah mengetahui bahwa Dimara adalan pasukan Indonesia, Andreas Werebai lari meninggalkan Etnabay, sedangkan Dimara dan pasukannya melanjutkan perjalanan menuju Ettahima dari Essanuai.

Robert Abujani dan Gerson Abujani, warga dari Hairapara menyebutkan bahwa pada tahun 1962 Cornelis Kamakaula, Jeremias Awujani, Gerson Awujani, Lukas Awujani dan Jonathan Awujani mengantarkan pasukan Dimara dari Simanewa (Teluk Etna) (Wawancara 23 Februari 2009). Di tempat itu, Dimara mengibarkan bendera Merah Putih sambil memekikkan "merdeka". Setelah itu dari sana, mereka berjalan kaki menuju Ettahima. Gerson yang waktu itu ikut mengantar Dimara dengan perahu masih ingat dengan baik lagu Kayo yang diajarkan 
oleh Dimara. "Ijo jana muwerie pasa bonia, andoro wasia jana muwerie, ijo jana muwerie..."

Menurut Meliaki Rumaterai, tokoh masyarakat dari Paparo, Letnan Dimara merekrut penduduk kampung untuk menjadi anggota pasukannya dengan cara memberikan senjata. Dari 29 orang anggota pasukannya, hanya Dimara dan tiga orang yang bertahan hidup (Wawancara 23 Januari 2009). Dimara dikenal oleh pejuang Indonesia sebagai orang yang keras hati dan penuh percaya diri. Kata-katanya selalu diingat oleh Meliaki, "Saya toki tifa di Jakarta, Irian Barat berdansa." Dimara bersembunyi di pintu Napuri (Kali Omba) dan bertempat tinggal dengan dua orang bersaudara yakni Natalus Kamakaula dan Kaspalina Kamakaula.

Pada saat kapal Belanda "Weremias" datang, Natalus membangunkan Dimara yang sedang tidur. Dimara melarikan diri dari Napuri menuju Epauri (kampung tua sebelum pindah ke Wosokuno). Kemudian, ia berjalan menuju ke Aria Napuri yakni di tengah-tengah antara Ettahima dan Kiruru. Di daerah ini, Dimara ditangkap oleh Guru Yusuf Waita (guru penginjil di Ettahima). Orang-orang kampung Ettahima memberi dia makan, kemudian mengepung dan menangkapnya. Dimara tidak bisa melakukan perlawanan yang berarti karena senjatanya sudah karatan dan macet.

Kisah penyusupan anak buah Dimara juga didapat dari Danau Yamor Besar. Menurut Hanok Kamandirei, Kepala Suku Napiti di Urubika, ada pasukan Indonesia yang sampai di danau Yamor Besar, komandannya ialah Ludwig Mandacan (Wawancara Hanoch Kamandirei, 23 Januari 2009). Belanda yang mengetahui kedatangan pasukan tersebut, kemudian mengirim pesawat terbang dan mendarat di Tanjung Gareda (Tanjung Kotipura). Pasukan Indone- sia kemudian melancarkan tembakan ke arah pasukan Belanda yang lari naik ke gunung meninggalkan speed boat di pantai. Setelah tembak-menembak di danau Yamor, 8 anggotanya ditembak mati tentara Belanda dan Ludwig menyerah, ditahan di Urubika dan diterbangkan ke Biak, selanjutnya dikembalikan ke Jakarta sesudah persetujuan damai. Pada waktu itu, sebagian masyarakat Yamor yang pro-Indonesia memberikan sagu dan melaporkan perkembangan situasi di Yamor. Namun perlu diingat, bahwa sebagian masyarakat Yamor pada umumnya pro-Belanda dan menjadi mata-mata Belanda.

Sesudah penangkapan Dimara, Residen Fakfak Tuan Jansen datang ke danau Yamor untuk bertanya siapasiapa yang memberi makanan kepada Letnan AJ Dimara dan Mandacan. (Wawancara Hanoch Kamandirei, 23 Januari 2009). Sesudah itu, dua warga Kampung Urubika, Bastian Komboi dan Lazarus Wermina, ditangkap Belanda. Waktu diinterogasi, mereka mengaku dipaksa memberikan perahu dan mendayung oleh tentara Mandacan. Kepala Kampung Melianus Akudiome dan wakilnya Piet Rumatera datang untuk membebaskan kedua orang itu agar tidak dibawa oleh Pasukan Belanda.

Sementara pasukan Antaribaba juga mengalami nasib yang hampir sama dengan pasukan Dimara. Menurut catatan resmi, pasukan ini dapat mencapai sasaran dan mengadakan kontak senjata dengan Pasukan Belanda. Pada beberapa kali pertempuran, banyak dari mereka yang gugur atau tertangkap Belanda. Letnan Antaribaba sendiri ditangkap oleh Pasukan Belanda di perbatasan Kaimana-Nabire. Sebagian dari mereka ditahan di Digul dan dilepaskan setelah tercapai Perjanjian New York tahun 1962.

Pasukan Gerilya 100 yang dipimpin ke Letnan Hengki Antaribaba men- 
darat di Omba Nariki. Menurut Suud Moy, orang tua dari Kampung Nariki, baik Letnan A.J Dimara maupun Antaribaba masuk ke Teluk Etna dari arah Umar Pattawai (Wawancara Saud Muy \& Frans Omapoka, 28 Januari 2009). Teryanus Kotipura, adalah salah satu anggota Mobile Police Belanda di Fakfak yang dikirim ke Teluk Etna untuk mengamankan Teluk Etna dari gangguan tentara Indonesia. Perintah dari Belanda adalah untuk menangkap dan jangan sampai ada tembakmenembak. Teryanus lalu pergi ke Tanjung Nariki untuk menangkap dan memenjarakan pasukan Indonesia. Pasukan Letnan Hengki akhirnya terdesak mundur sampai perbatasan Nabire, 25 orang anggota pasukannya ditawan oleh Pasukan Belanda di Kooaburi, daerah perbatasan Teluk Etna dan Nabire.

Namun demikian beberapa peristiwa pertempuran di tengah laut belum diceritakan oleh penduduk di Teluk Etna (Sugiarto, 1995: 232). Catatan resmi Pemerintah Indonesia mengatakan bahwa Pasukan Gerilya 600 (PG-600) yang bemarkas di Kepulauan Aru diberangkatkan Maret 1962 dengan 3 perahu di bawah pimpinan Maksum menuju Sungai Yera dengan kekuatan 31 orang. Salah satu perahu ditembak pesawat Belanda di daerah antara Teluk Etna dan Kepulauan Watu Belah yang menewaskan 7 orang prajurit. Pasukan yang selamat berjumlah 24 orang di bawah Oktavianus Marani.

Berbeda dengan penerjunan di Teluk Arguni, pendaratan di Teluk Etna banyak menemui kesulitan. Meskipun sedikit, masih ada masyarakat yang memberikan dukungan. Cerita lisan Letnan Dimara menunjukkan bahwa dia berusaha merekrut pasukan dari orang Papua tetapi akhirnya ditangkap sendiri oleh orang Papua yang pro-Belanda. Fakta menunjukkan bahwa masyarakat di daerah ini masih terbatas membuka komunikasi dengan dunia luar. Etnabai sendiri baru dibuka sekitar tahun 1938. Hal ini berbeda dengan Namatota atau Kaimana yang telah berinteraksi dengan orang-orang Indonesia sebelum kedatangan Belanda. Namun, hal ini tidak dapat dipahami secara deterministik bahwa interaksi dengan orang Indonesia akan mendorong orang Papua bersikap pro-merdeka. Interaksi dalam bentuk hubungan perdagangan ataupun sosialisasi politik telah memberikan kesadaran baru kepada orang Papua untuk melihat dirinya dalam konteks imagined community yang disebut dengan Indonesia.

Selain Teluk Arguni dan Teluk Etna, pasukan payung juga diterjunkan di daerah yang sekarang ini menjadi bagian dari Distrik Kaimana. Daerah ini menarik jika dilihat dari aspek politik, ekonomi, dan sosial budaya karena Kota Kaimana menjadi pusat dari proses politik yang mempengaruhi daerah-daerah lainnya. Paling tidak, keputusan politik kepala-kepala kampung atau kepalakepala suku di daerah ini sedikit banyak dipengaruhi oleh keputusan-keputusan politik dari para elit di Kaimana.

\section{Penentuan Pendapat Rakyat 1969}

Pepera adalah salah satu hasil dari Perjanjian New York antara Indonesia dan Belanda yang ditandatangani pada 15 Agustus 1962. Pepera diselenggarakan oleh Pemerintah Indonesia di bawah pengawasan UNTEA-PBB pada periode waktu antara 14 Juli sampai dengan 2 Agustus 1969. Pelaksanaan Pepera dilakukan di delapan kabupaten dan di setiap kabupaten dibentuk sebuah Dewan Musyawarah Pepera (DMP Kabupaten). Setiap DMP terdiri atas wakil-wakil daerah yang dipilih oleh rakyatnya, wakil-wakil yang dipilih 
Paramita Vol. 25, No. 1 - Januari 2015

Tabel 1. Jumlah Penduduk dan Wakil Rakyat Papua dalam Pepera

\begin{tabular}{llll}
\hline No. & Kabupaten & Jumlah penduduk & Wakil \\
\hline 1. & Jayapura & 81.246 & 110 \\
2. & Teluk Cenderawasih & 93.230 & 130 \\
3. & Manokwari & 53.290 & 75 \\
4. & Sorong & 86.840 & 110 \\
5. & Fakfak & 38.917 & 75 \\
6. & Merauke & 141.373 & 175 \\
7. & Paniai & 156.000 & 175 \\
8. & Peg Jayawijaya & 165.000 & 175 \\
& & & 1.025 \\
\hline
\end{tabular}

Sumber: Djamhari, 1995: 268

oleh ormas, dan unsur tradisional para kepala suku. Wakil rakyat Papua yang dipilih untuk memberikan suara dalam Dewan Musyawarah Pepera (DMP) sebanyak 1.062 orang.

Mayoritas (99\%) anggota DMP memilih berintegrasi dengan Indonesia. Hasil Pepera tersebut disahkan oleh Sidang Umum PBB pada 19 November 1969 melalui Resolusi No. 2504. Resolusi tersebut diajukan oleh 6 negara, diterima oleh 84 negara, dan tidak berpendapat sebanyak 30 negara. Pepera tidak hanya dapat dilihat dari aspek politik dan legalitas, namun juga harus dilihat bagaimana tokoh-tokoh masyarakat memaknai peristiwa politik tersebut pada masa awal integrasi. Bagaimana memaknai Pepera adalah lebih penting dari hasil Pepera itu sendiri karena kita akan melihat bagaimana tokoh-tokoh masyarakat menempatkan peristiwa-peristiwa politik dalam konstruksi subjektif mereka.

Menurut catatan resmi Pemerintah Indonesia, nama-nama anggota DMP Fakfak berjumlah 75 orang. Namun, nama-nama tersebut tidak disertai oleh organisasi, suku, atau daerah yang diwakilinya. Menurut Kepala Su- ku Koiwai, anggota DMP dari Kaimana Kota adalah Muhamad Rais Aituarouw (Raja Komisi), Muh. Kasim Ombaier (Raja Namatota), dan Moy Balawaar. Anggota DMP yang berasal dari Teluk Etna ialah Andreas Werebai (Semimi) dan Muh. Thoyib Amerbai (Kayu Merah) (Wawancara Sidiq Fuarada, 28 Desember 2008). Ucapan Andreas Werebai pertama kali di Semimi sehabis mengikuti musyawarah para anggota DMP di Fakfak ialah sebagai berikut.

Mulai sekarang, kamu orang tidak usah ke sana kemari karena Indonesia telah membebaskan New Guinea dan kita semua dari penjajahan Belanda. Kita tidak usah dan tidak perlu gelisah akan masa depan anak cucu kita. (Wawancara Abdul Mat Puarada, 5 Januari 2009)

Saksi sejarah lainnya, Samuel Fenitiruma (Wawancara 2 Februari 2009) menceritakan bahwa delegasi DMP dari Distrik Kaimana selengkapnya adalah sebagai berikut: Samuel Fenitiruma (pemuda Kaimana), Jusuf Pati Sausiwa (imam Kaimana), Arnold Namsau (Tanggrome), Hamzah Furu (Arguni), 
Johan Sarera (Arguni), Rajab Nanggewa (Lobo), Andreas Werebai (Semimi), Rajab Amerbai (Kayu Merah).

Jika dilihat dari nama-nama marga dan berdasarkan catatan resmi pemerintah Indonesia serta wawancara dengan informan di Kaimana, maka keseluruhan anggota DMP Fakfak yang berasal dari Kaimana adalah: Kasim Ombaier, Nataniel Wariensi, Johan Sarera, Jusuf Waita, Sadik Puarada, Moh Thaib Amerbai, Semuel Fenitiruma, Jusuf Patisahusiwa, Hamzah Furu, Moy Lawai, Moh Rais Aituarauw, Manaf Watora, Arnold Namsau, Moi Balawar, Radjab Nanggewa dan Andreas Werebai.

Rombongan DMP ini dipimpin oleh Samuel Fenitiruma. Mereka semua diseleksi oleh Tim dari Kabupaten Fakfak di bawah Ali Murtopo. Jumlah DMP Kabupaten Fakfak mencapai 75 orang dari Fakfak, Kokas, Kaimana, Mimika Barat, dan Mimika Timur. Sidang tersebut dihadiri oleh Tuan Ortiz San dari PBB. Ortiz memberikan pengantar sebagai berikut: "Saudara-saudara hari ini duduk untuk suatu kesempatan menentukan generasi anda ke depan. Anda bebas menentukan apakah ingin memilih bergabung dengan Pemerintah RI atau lepas dari Indonesia." Giliran berbicara pertama diberikan kepada Sem Fenitiruma, menyusul Ismail Bau, lalu Galin Reasa. Ucapan Sem Fenitiruma di depan Sidang DMP.

Pertama, saya hormati Tuan Ortiz San dari PBB, Bupati Fakfak AS Onin. Saya mewakili KPS Kaimana. Hari ini kita mulai bersidang, Kita masyarakat Kaimana memilih bergabung dengan Pemerintah Republik Indonesia. Saya hanya menyarankan kalau kita gabung dengan Pemerintah RI, saya sarankan kepada Bapak Amir Machmud agar Pemerintah memberikan otonomi yang seluas-luasnya kepada putra-putri Kaimana supaya mereka belajar di Jawa. Secara formal, kita sudah gabung, saya meminta otonomi luas kepada Papua.

Kemudian, wartawan-wartawan Indonesia memotret dan mengerubutinya serta menanyakan apakah yang dimaksud dengan ucapanya "kembali ke nol". Sem Fenitiruma menjawab apabila Pemerintah RI tidak memberikan otonomi luas kepada putra-putri Kaimana berarti Papua kembali ke nol seperti sebelum penjajahan Belanda.

Sesudah sidang selesai, mereka semua dibawa ke KM Ambeto yang berlabuh di Pantai Panjang untuk makan siang bersama Mendagri Amir Machmud. Bapak Menteri mengatakan kepada Samuel: "Sdr Samuel akan saya berikan tugas belajar atau DPRD?" Samuel memilih belajar ke Jawa karena untuk kepentingan jangka panjang. Ketika ditanya apakah ada intimidasi, Samuel mengatakan tidak ada. Namun, diakui secara jujur memang ada pengawalan khusus kepada anggota-anggota DMP. Setiap anggota DMP ada yang mengurus kebutuhan satu orang anggota RPKAD yang berpakaian sipil. Mereka menjaga dan melayani semua keperluan anggota DMP. Anggota-anggota DMP ditampung di asrama PVS Fakfak, sedangkan tempat musyawarah di Gedung Pepera (sekarang menjadi Perpustakaan Fakfak). Tujuan pengawalan itu adalah agar tidak ada intervensi dari luar yang dapat mengganggu pemikiran dan pendapat anggota DMP, supaya tidak pergi ke sana ke mari dan tidak ada orang yang datang untuk mempengaruhi mereka.

Waktu itu terdapat juga anggota DMP yang tidak setuju dengan integrasi Papua ke Indonesia yakni Edward Hegemur dari Fakfak. Edward berbicara sambil menunjuk peta Irian sebagai berikut.

Hai, Tanahku Papua, hai kenapa hari ini kau tanya saya. Belum tahu, saya 
lahir di udara, lahir di laut, saya lahir di Tanah Papua ini. Perjuangan Nikolas Tanggama, Nikolas Jouwe, dan Markus Kasiepo, perjuangan saudarasaudara adalah perjuangan kami orang Papua. Tuan Ortiz San tulis nama saya, saya lahir di tanah ini dan hari ini saya ajak siapa yang mau merdeka berdiri semua.

Waktu itu tidak ada yang berdiri kecuali Ortiz San yang memang sudah berdiri. Edward selanjutnya berbicara seperti ini: "Apabila saya mati ditembak hari ini, nisan saya hendaklah ditulis Pahlawan Papua. Hari ini juga saya menyatakan Papua merdeka."

Wartawan luar negeri kemudian mengerubung, bahkan sempat membobol tembok pembatas. Mereka menulis pernyataan Edward Hegemur. Setelah itu Edward dipanggil Kodim tetapi dia tidak diberi tindakan apapun karena Presiden Soeharto sudah memerintahkan agar tidak boleh berbuat apa-apa atas suara resmi, kalau ada yang menyimpang 1 atau 2 itu hal biasa. Saat pemilihan Ketua DPRD Fakfak, dia mengatakan bahwa suaranya yang proPapua Merdeka dalam Sidang DMP menunjukkan Pepera dilaksanakan secara bebas dan hal ini mengangkat harkat dan martabat Pemerintah RI. Akhirnya dia terpilih menjadi Ketua DPRD Fakfak.

Sepulang dari Fakfak, kapal yang membawa anggota DMP Kaimana yakni kapal "Betet" kandas di Pulau Kilimala (Wawancara Iklaf Fitmatan, 6 Januari 2009). Salah anggota DMP utusan dari Pulau Kilimala mengambil alih kemudi yaitu Moy Balawaar. Setelah kapal ditambal, perjalanan dilanjutkan ke Kaimana. Pada waktu itu, Kepala Kampung Kilimala ialah Kapitan Manaf Samay.

Perlu menjadi catatan bahwa pada waktu itu banyak juga pihak-pihak yang tidak setuju dengan Pepera. Menurut
Wakil Ketua Suku Kambrauw di Kaimana, Karel Meigi (Wawancara 13 Februari 2009), Pepera cacat hukum karena tokoh -tokoh masyarakat dipaksakan untuk memilih Indonesia dan Pemerintah Indonesia tidak menetapkan one man one vote. Wakil-wakil masyarakat Papua dipilih oleh Pemerintah sebanyak 1.025 orang, untuk menyampaikan aspirasi rakyat Papua dalam Dewan Musyawarah Pepera (DMP). Karel Meigi sebagai saksi mata menceritakan: "Saya melihat dalam jarak 20 meter di tengahtengah antara SD Yapis dan SD YPPK Kaimana ada sebuah bilik, orang-orang tua dimasukkan bilik oleh tentara dan ditanya satu persatu siapa yang mau merdeka? Kepala-kepala kampung juga dimasukkan ke bilik itu dan ditanya siapa yang mau merdeka. Mereka menjawab ikut Indonesia."

Menurut pandangan Karel Meigi, rakyat Papua sebenarnya ingin merdeka baik Islam maupun Kristen (Wawancara 13 Februari 2009). Hanya beberapa kelompok orang Islam yang mendapat pengaruh politik dari republik yakni Kepala Kampung Seraran, Hamzah Furu. Mereka jelas-jelas diistimewakan untuk mempengaruhi orang lain menandatangani pernyataan bergabung dengan RI. Juga Ketua Pemuda Kaimana dari Teluk Kambrauw, Samuel Fenitiruma memilih pro-republik dalam Pepera. Pada waktu itu, antarorang Papua sudah menaruh rasa saling curiga satu sama lain. Karel Meigi menceritakan bahwa pada dasarnya, orang Papua menilai orang-orang non-Papua di Tanah Papua pro-republik. Ketika datang Pepera, semua sudah takut untuk bersuara kecuali Edward Hegemur, mantan bestuur di Kaimana.

Menurut Karel Meigi, basis pendukung Indonesia ialah masyarakat muslim Kampung Seraran dan Kaimana Kota (Wawancara 13 Februari 2009). Sedangkan, hampir semua kampung- 
kampung Kristen memilih pro Papua merdeka. Ia sendiri waktu itu memilih pro Papua merdeka karena menganggap Papua sebagai sebuah pulau khusus bagi orang-orang Melanesia yaitu orang -orang yang berambut keriting dan berkulit hitam. Namun ada juga orangorang Papua yang telah berasimilasi dengan para pedagang dari Indonesia di pantai-pantai. Mereka ialah orang Koiwai. Bahasa mereka tidak dapat disebut sebagai bahasa Seram dan juga tidak dapat disebut sebagai bahasa Papua karena campuran antara bahasa-bahasa Seram dan bahasa-bahasa Papua. Orang Papua menyebut suku Koiwai sebagai suku antarpulau. Menurut Karel Meigi rakyat Papua mencurigai bahwa orangorang suku Koiwai ini memihak Indonesia karena nenek moyangnya ada di Maluku. Namun Karel sendiri tidak tahu sikap politik Raja Kasim Ombaier. Menurutnya rakyat Papua mencurigai Raja Kasim Ombaier sebagai orang di belakang layar kelompok-kelompok masyarakat yang pro-Indonesia karena nenek moyangnya juga berasal dari Indonesia. Namun, Raja Kasim sendiri tidak pernah menyatakan dengan jelas di depan publik bahwa dia pro-Indonesia seperti Ghalin Reasa dan Rumalam (Koiwai).

Karel Meigi juga mengatakan bahwa bangsa yang dijajah perlu diberikan kemerdekaan sehingga di sana ada gerakan Papua Merdeka (Wawancara 13 Februari 2009). Mereka yang ingin merdeka ialah para kapitan, sangaji yang berasal dari kampung-kampung Kristen. Belanda sebenarnya memimpin bangsa ini untuk merdeka, jadi rakyat Papua juga tidak suka dengan Belanda sehingga usulan dan aspirasi mereka ialah meminta kemerdekaan. Dalam pidatonya di Fakfak, Nikolas Tanggahma mengatakan bila Papua merdeka maka orang Papua bisa sejajar dan bekerja sama dengan bangsa-bangsa lain.
Kemudian berdatangan Saul Hindom dan Fritz Kurihio, mahasiswa Papua di Universitas Leiden, untuk berkampanye Papua merdeka.

Elit Papua pada waktu itu menyadari bahwa integrasi Papua ke Indonesia tidak bisa dilepaskan dari peranan Amerika Serikat yang sedang menghadapi ekspansi politik komunis di Asia Tenggara. Bila Amerika Serikat tidak membantu Indonesia, maka Indonesia kemungkinan besar akan dikuasai komunis. Baik Amerika Serikat, Belanda, dan Indonesia dalam perspektif sebagian elit Papua dan nasionalis Papua telah "melecehkan" orang Papua karena orang Papua dianggap tidak ada dan dikorbankan untuk kepentingan politik.

Sementara dalam perspektif para nasionalis Papua tujuan pembentukan GRIB adalah untuk memperbesar pertentangan antara golongan yang pro dan kontra integrasi dengan Indonesia. Sebelum Pepera dimulai, beberapa orang pro-Papua merdeka di Kaimana seperti Sakios Irini, Frans Bari, dan Bahudin Fenitiruma ditangkap oleh tentara Indonesia dan dipenjara di Kalisosok Surabaya dengan tuduhan mendukung Papua merdeka (Wawancara Karel Meigi, 13 Februari 2009). Namun, atas desakan PBB, mereka dilepaskan dan dipulangkan ke Kaimana. Pada waktu Pangdam Trikora dijabat oleh Brigjend Sarwo Edhie Wibowo, Karel Meigi ditahan oleh Koramil Kaimana karena laporan dari pihak-pihak tertentu bahwa dirinya pro-Papua Merdeka. Namun tuduhan pada Karel Meigi ikut gerakan Papua merdeka tidak terbukti. Pada malamnya, ia dilepaskan setelah menandatangani pernyataan: (1) jujur menyimpan rahasia negara, (2) bersedia menjadi pegawai negeri RI, dan (3) wajib melaporkan isu-isu yang terkait dengan masyarakat. 
Setelah penyelenggaraan Pepera, Papua menjadi bagian dari Indonesia baik secara de jure maupun de facto. Setelah itu, Pemerintah Indonesia mengadakan penataan administrasi pemerintahan. Namun status Kaimana tetap menjadi bagian dari Kabupaten Fakfak dan berkedudukan sebagai kecamatan. Selama rejim Orde Baru berkuasa, ide-ide tentang pembentukan Kabupaten Kaimana tidak mendapatkan respon yang signifikan dari Kabupaten Fakfak maupun Provinsi Irian Jaya. Pergantian rejim pemerintahan pada tahun 1998 memungkinkan ide pemekaran Kabupaten Fakfak dilaksanakan.

\section{SIMPULAN}

Sejarah perkembangan pemerintahan di Kaimana dalam tulisan ini didasarkan dengan lebih banyak mengandalkan cerita-cerita lisan dan pengalaman objektif para saksi sejarah. Tentu saja pengalaman-pengalaman objektif tersebut telah di-cross-check antarinforman dan data-data literatur yang terkait. Bertolak dari cerita tentang penerjunan di Teluk Arguni dan Kaimana serta pendaratan di Teluk Etna pada masa Trikora, kita dapat mengetahui bahwa sejarah Kaimana pada masa awal integrasi dengan Indonesia adalah sejarah perlawanan terhadap Belanda yang melibatkan para pejuang dan pasukan-pasukan TNI yang tergabung dengan Pasukan Trikora. Jika dilihat dari fenomena tersebut, maka sejarah politik Kaimana pada masa Orde Baru adalah sejarah membangun representasi ke-Indonesia-an yang dihadapkan pada identitas politik ke-Papua-an hasil konstruksi pemerintahan kolonial Belanda. Dari sejarah lisan tersebut kita mengetahui bagaimana para guru, polisi, dan pejabat pemerintah Belanda menanamkan identitas politik ke-Papua-an yang didasarkan atas perbedaan ras.

Namun demikian, orang-orang Kaimana bukanlah subjek yang tidak berdaya karena mereka juga mengalami proses sosialisasi politik, terutama pada level elit yakni orang-orang Kaimana yang dibuang di Digul dan yang berinteraksi dengan para pendatang lainnya. Sosialisasi politik itu memberikan orang-orang Kaimana alternatif untuk mendukung integrasi dengan Indonesia.

Raja-raja Kaimana dan para ulama di Kaimana terbukti berperan aktif dalam mendukung integrasi Papua ke Indonesia, sekaligus membangun identitas politik ke-Indonesia-an. Kalangan nasionalis Papua menganggap kenyataan ini bisa terjadi karena mereka adalah orang-orang yang berdarah campuran antara orang Papua dan orang Maluku. Pada level empiris, kita dapat mengetahui bahwa sikap politik Raja Kasim sangat menentukan pandangan kepalakepala kampung untuk memilih Indonesia pada waktu Pepera. Andaikata pada waktu itu Raja Kasim Ombaier mendukung Belanda, mungkin saja sejarah akan bercerita lain dan mungkin saja para kepala kampung itu akan mengikuti Edward Hagemur dalam DMP di Fakfak yang mendukung Papua merdeka.

Perubahan politik nasional pasca reformasi 1998 telah ikut berpengaruh atas perkembangan sejarah pemerintahan di Kaimana. Saat itu, ketika tuntutan Papua merdeka mulai diteriakkan, tuntutan pemekaran Kabupaten Fakfak juga mulai diajukan kepada pemerintah provinsi dan pusat. Orang-orang Kaimana melihat bahwa dirinya lambat berkembang dalam pembangunan selama masih berada di bawah Pemerintahan Kabupaten Fakfak. Oleh karena itu mereka menuntut untuk berkembang menjadi kabupaten sendiri yang otonom. Proses politik yang panjang 
dari tahun 1998 sampai tahun 2003 telah mendorong terbentuknya Kabupaten Kaimana. Pada akhirnya, orang-orang yang mendukung Papua merdeka juga mendukung pembentukan kabupaten Kaimana dalam bingkai Otonomi Khusus Papua.

Hal yang paling menarik dalam tulisan ini adalah kritik terhadap teks sejarah yang diproduksi oleh rejim Orde Baru tentang Trikora. Wacana mengenai Trikora dalam perspektif nasionalisme Indonesia selalu merujuk pada nama besar Presiden Sukarno dan Mayjend Soeharto sebagai Panglima Mandala. Namun, dalam praktiknya seperti disampaikan dalam cerita-cerita lisan, masyarakat di Kaimana lebih mengenal dan memiliki kesan yang baik terhadap Mayor Untung Syamsuri. Tindakan Mayor Untung mengadopsi seorang anak Papua dapat dimaknai bahwa dia mencoba membangun representasi keIndonesia-an di Papua dengan cara yang manusiawi.

\section{DAFTAR PUSTAKA}

Ahmad, M. 1990. Sejarah Singkat Perjuangan Kemerdekaan. Kaimana.

Chauvel, R. 2005. Constructing Papuan Nationalism: History, Etnicity and Adaptation. Washington DC: East West Center.

Djamhari, S.A dkk.. 1995. Tri Komando Rakyat Pembebasan Irian Barat (1995). Jakarta: Markas Besar TNI AD

Drooglever, PJ. 2010. Tindakan Pilihan Bebas. Yogyakarta: Kanisius

Imran, A. 1971. Sedjarah Perkembangan Angkatan Darat. Jakarta: Pusat Sejarah ABRI, Departemen PertahananKeamanan.

Imparsial. 2011. Sekuritisasi Papua, Implikasi Pendekatan Keamanan Terhadap Kondisi HAM di Papua. Jakarta: Imparsial

Indobat Community. 2008. "Organisasi Paskas TNI-AU". Dalam http://indobattcommunity.blogspot.com/2008/11/ operasisejarah-dan-organisasipaskhas.html. Diakses 1 Januari 2010.

Nota Perang Trikora di Kaimana, J.J. Nortier dan J.W. de Leeuw (tanpa tahun), Het 6e Infanterie Bataljon in Nieuw-Guinea (Stichting Reünie Nieuw-Guineamilitairen)

Sugianto, L. 1995.. Caturwindu kemenangan Perjuangan Trikora. Jakarta: Yayasan Perintis Irian Barat.

\section{Wawancara}

Abdul Mat Puarada di Kaimana pada 5 Januari 2009.

Abdul Qodir Kurita di Kaimana pada Januari 2009.

Abu Werfete di Kaimana pada 24 Desember 2008.

Christian Upia dan Fredrik Karafe di Warifi Teluk Etna pada 4 Februari 2009.

Dipen Werfete di Kampung Gusimawa Teluk Arguni pada 23 Desember 2008.

Fredrik Essuruw di Warwasi, Teluk Arguni, 24 Desember 2008.

Hanoch Kamandirei, di Urubika Yamor pada 23 Januari 2009.

Harun Sabuku, di Kaimana 1 Februari 2009.

Idrus Al Hamid, Malang, September 2010

Imam Iklaf Fitmatan di Kaimana pada 6 Januari 2009.

Imam Ubas Nabombo di Kaimana pada 19 Januari 2009.

Imam Warwasi, Daud Werfete, di Warwasi, Wesswasa, 22 Desember 2008.

Karel Meigi, di Kaimana pada 13 Februari 2009.

Meliaki Rumaterai di Paparo Teluk Etna pada 23 Januari 2009.

Mohammad Hassan Rahanyamtel, Langgur, 23 dan 24 Oktober 2010

Moy Amir Kamakaula di Kayu Merah pada 21 Januari 2009.

Oktavianus Safara di Morano, Kaimana pada 1 Februari 2009.

Robert Awujani dan Gerson Awujani di Hairapara Teluk Etna 23 Januari 2009.

Robert Essuruw di Wesswasa, Teluk Arguni, 22 Desember 2008.

Sadik Fuarada, di Kamung Warwasi Teluk Arguni pada 21 desember 2008.

Saifudin Furu di Kaimana pada 22 Desember 2008 . 
Paramita Vol. 25, No. 1 - Januari 2015

Samuel Fenitiruma di Kaimana pada 2 Feburari 2009.

Saud Muy dan Frans Omapoka di Nariki Teluk Etna pada 28 Januari 2009.

Taha Al Hamid, 10 Agustus 2010.
Terianus Kotipura di Urubika Yamor pada 24 Januari 2009.

Terryanus Kotipura di Urubika Yamor 24 Januari 2009. 